\title{
Resistivity structure of high-angle subduction zone in the southern Kyushu district, southwestern Japan
}

\author{
Masahiro Ichiki ${ }^{1}$, Norihiko Sumitomo ${ }^{2}$, Tsuneomi Kagiyama ${ }^{1}$ \\ ${ }^{1}$ Earthquake Research Institute, University of Tokyo, 1-1-1 Yayoi, Bunkyo-ku, Tokyo 113-0032, Japan \\ ${ }^{2}$ Faculty of Humanities and Sciences, Kobe Gakuin University, 518 Arise, Ikawadani-cho, Nishi-ku, Kobe 651-2180, Japan
}

(Received January 19, 2000; Revised May 2, 2000; Accepted June 14, 2000)

\begin{abstract}
Magnetotelluric observations were carried out in the southern Kyushu district of southwestern Japan to investigate the characteristics of the electrical resistivity structure of a high-angle subduction zone. We constructed a 2-D resistivity model parallel to the subducting plate motion by using the inversion technique with the Akaike Bayesian Information Criterion (ABIC) smoothness constraint. The general features of the obtained resistivity structure are as follows: (1) a conductive block (below $1 \Omega \cdot \mathrm{m}$ ) is found beneath the volcanic zone and is widespread bilaterally below $40 \mathrm{~km}$ depth, (2) a resistive block (about $1000 \Omega \cdot \mathrm{m}$ ) distributes from 10 to $25 \mathrm{~km}$ depth in the forearc region and (3) a conductor $(1 \sim 30 \Omega \cdot \mathrm{m})$ is embedded beneath the resistive block, which may correspond to the negative Bouguer gravity anomaly observed in this region. We propose the following for the high-angle subduction zone: A serpentinized block is generated in the lower crust of the forearc region and a partial melting and hydrothermal fluid are well developed beneath the volcanic front.
\end{abstract}

\section{Introduction}

Electrical resistivity structures of subduction zones have been investigated since the 1980's and have contributed to wards recognizing the role of the dehydration process of the subduction zone. Kurtz et al. (1986), Utada (1987), Hyndman (1988) and Wannamaker et al. (1989) investigated the resistivity structures of the subduction zones where intermediate and deep dip angles (Jarrard, 1986) are from $30^{\circ}$ to $45^{\circ}$ and revealed the following features: (1) a conductive dipping layer lies on the subducting slab and (2) a lower crust conductor is found beneath the volcanic fronts. On the other hand, in a low-angle subduction zone, a different type of resistivity structure has been detected by recent studies. For example, Shiozaki (1993) investigated the resistivity structure in Shikoku Island, southwestern Japan, where the Philippine Sea plate subducts at a low angle smaller than $20^{\circ}$, and showed that no dipping conductive layer lies on the subducting slab. Such a difference of resistivity structure can be possibly explained by the subduction angle or evolution of the subduction zone (Kanamori, 1977; Uyeda and Kanamori, 1979). The process of subduction starts with lowangle thrusting. Then the oceanic plate descends to a greater depth and inclines with a higher angle as the subduction proceeds. Lastly, the oceanic plate sinks and the subduction angle becomes very large. During this last stage, the heat flow increases in the mantle wedge and the new subduction appears at the back arc region. Our final goal is to clarify the evolution of the subduction zone from the viewpoint of the dehydration process by compiling resistivity and other geo-

Copy right (C) The Society of Geomagnetism and Earth, Planetary and Space Sciences (SGEPSS); The Seismological Society of Japan; The Volcanological Society of Japan; The Geodetic Society of Japan; The Japanese Society for Planetary Sciences. physical parameters on the basis of the model of Kanamori (1977). However, so far, we have never come across electromagnetic investigations in high angle subduction zones except for that of Toh (1993). Hence, more investigations are required to establish the general features of the resistivity structures of high angle subduction zones.

The southern Kyushu district is one of the typical subduction zones in Japan, where the Wadati-Benioff zone dips over $60^{\circ}$ beneath the volcanic front, as shown in Fig. 1 (Yamazaki and Ooida, 1985; Nagamune and Tashiro, 1989; Kakuta et al., 1991; Ishihara and Yoshida, 1992). Moreover, the southern Kyushu district is remarkable for other characteristic tectonic features. For example, the extreme negative Bouguer gravity anomaly (Kobayashi et al., 1997) is observed in the forearc region (Fig. 2) and the Kirishima volcano group, Sakurajima volcano, and other volcanoes, which are the most active in Japan, are located along the volcanic front in the southern Kyushu district (Fig. 3). In spite of such geophysically interesting features, little is known about the subsurface structure except the uppermost crust in the southern Kyushu district. Therefore, the main purpose of this paper is to obtain a resistivity structure from the southern Kyushu district as a typical high-angle subduction zone that reflects the last evolution stage. We collected the magnetotelluric (MT) data, as shown in Fig. 1, and constructed a two-dimensional (2-D) resistivity model parallel to the subducting plate motion. This paper will also discuss the resistivity structure with special attention being paid to its possible relations to the Bouguer gravity anomaly and the active volcanism in this area.

\section{Magnetotelluric Data Acquisition}

The MT observation was carried out at the 10 sites shown in Fig. 1. In order to avoid the effect of Kinko Bay, we 


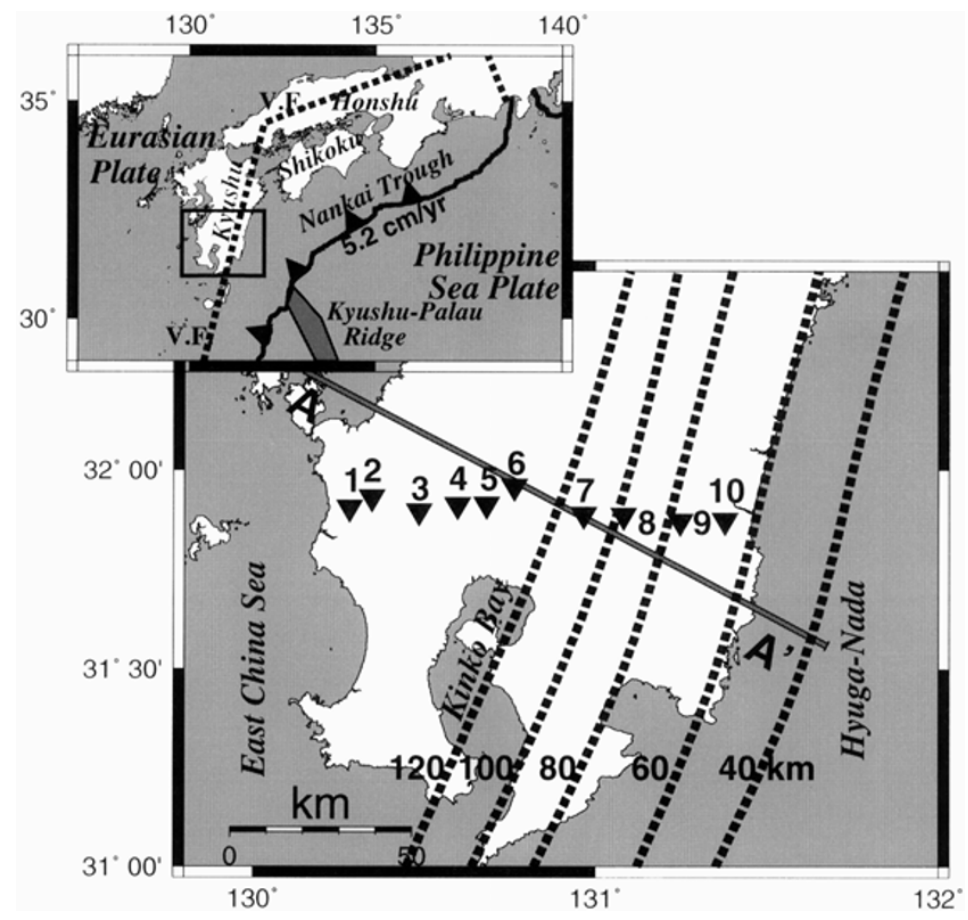

Fig. 1. Site locations for the magnetotelluric surveys (triangles). The A-A' is the profile line of pseudosection (Fig. 8) and 2-D resistivity model (Fig. 9). Dotted lines illustrate the isodepth of the Wadati-Benioff zone compiled by Yamazaki and Ooida (1985). The volcanic front approximately coincides wit the location of the $80 \mathrm{~km}$ isodepth of the Wadati-Benioff zone. Child map: the Philippine sea plate subducts beneath the Eurasian plate in the study area. The convergence rate was calculated as $5.2 \mathrm{~cm} / \mathrm{yr}$ (Seno et al., 1993).

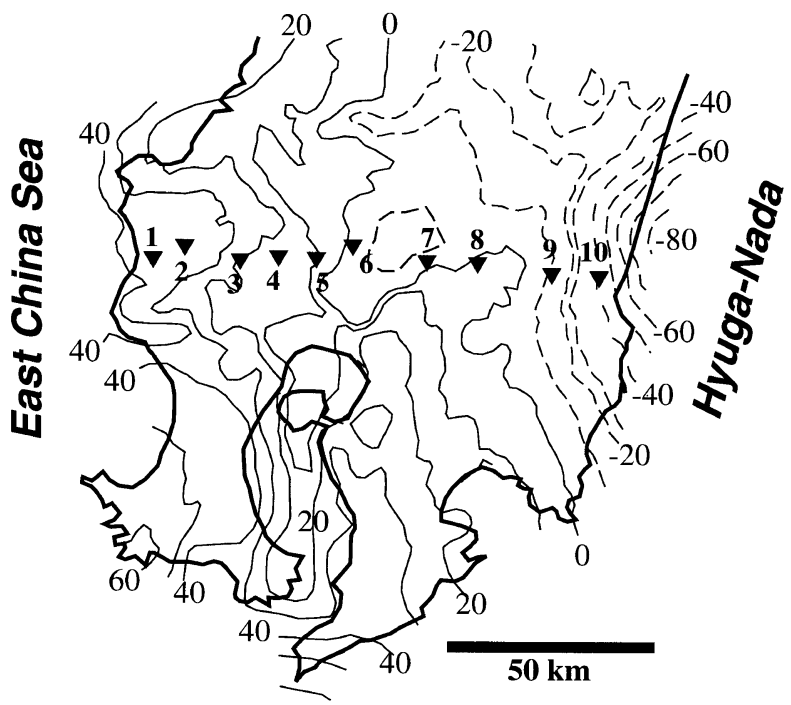

Fig. 2. Bouguer anomaly map of the southern Kyushu district (modified from Kobayashi et al., 1997). The average density is assumed to be 2.67 $\mathrm{g} / \mathrm{cm}^{3}$. Units are represented in mgal and the contour interval is $10 \mathrm{mgal}$. Reverse triangles represent the observation sites.

made the traverse as far as possible. Four MT instruments of the same type (Tierra Tecnica U43 system) were used in the observation, the resolution of which is $1 \mathrm{pT}$ in the magnetic field and $1 \mu \mathrm{V}$ in the telluric field, respectively. The internal clock system is continuously synchronized by a GPS clock signal and the accuracy of the internal clock is within $10^{-8}$. This clock system enabled us to carry out the MT experiments with a high sampling rate and reliable

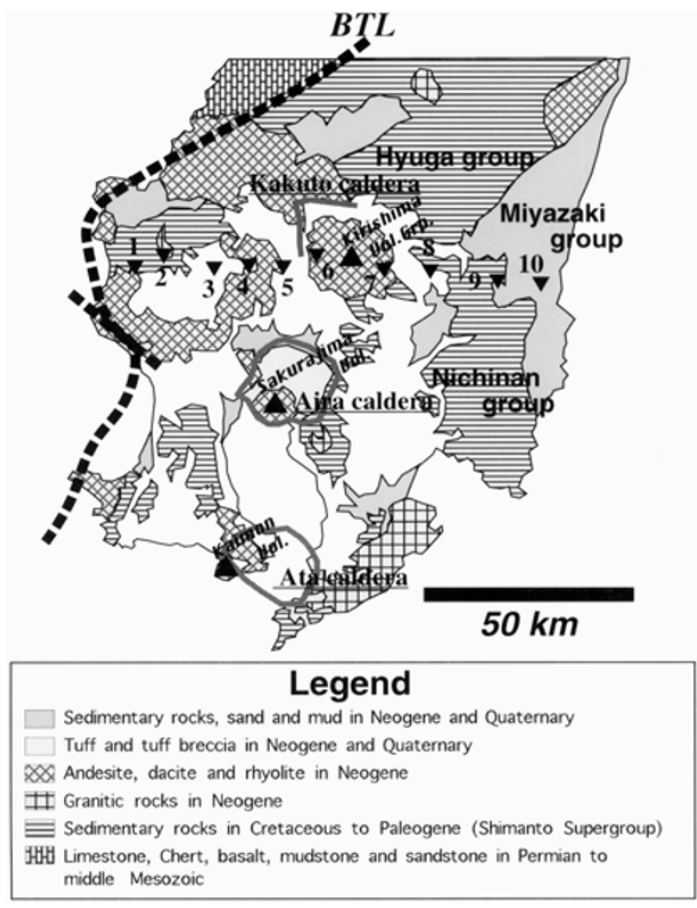

Fig. 3. Surface geological facies around the study area. Closed triangles represent active volcanoes. Gray lines are caldera rims. BTL represents Butsuzo Tectonic Line.

remote-reference processing (Gamble et al., 1979). Both the magnetic and telluric fields were digitally recorded in a flush memory (10 MB) and the typical recording duration was 3 weeks with a $1 \mathrm{~Hz}$ sampling rate and 1 hour with 


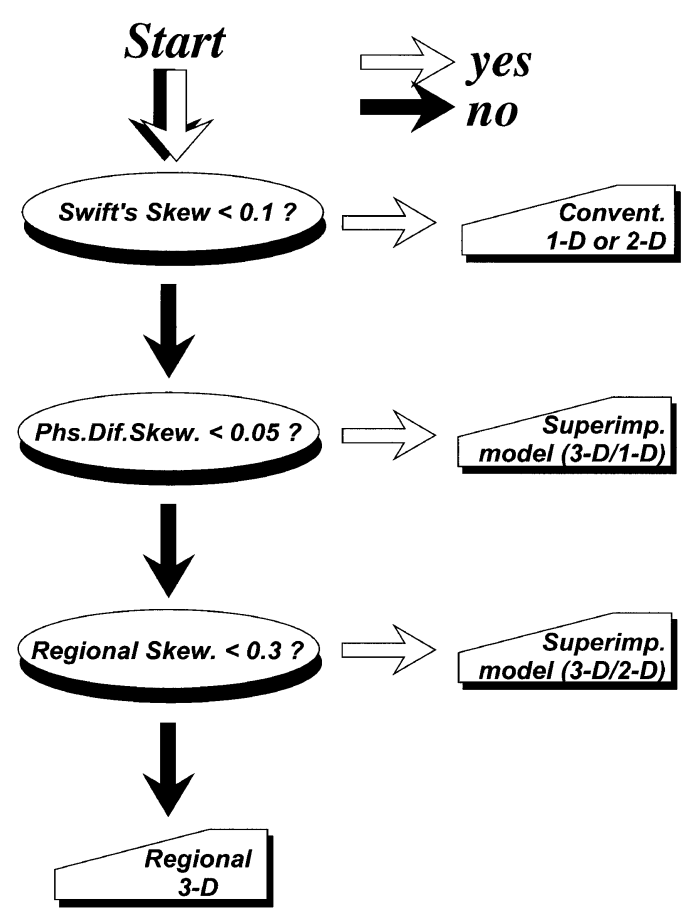

Fig. 4. Dimensionality criteria used in this study. Dimensionality is estimated by Swift's skew, phase difference skew and regional skew parameters. 3-D/1-D means a local 3-D and regional 1-D resistivity structure and 3-D/1-D means a local 3-D and regional 1-D resistivity structure, respectively. 'Convent.' and 'Superimp.' mean conventional and superimposed, respectively (cf. Bahr, 1991).

$128 \mathrm{~Hz}$, respectively. The total observation ran from 30 July to 22 September 1997 . The data quality and quantity were generally sufficient except those at Site 2 where battery troubles were encountered. The data of Site 2 were not used in the following analyses.

\section{Data Processing}

The MT impedance responses, $Z_{i j}(i, j=x, y)$, are defined as follows:

$$
\left[\begin{array}{c}
E_{x} \\
E_{y}
\end{array}\right]=\left[\begin{array}{ll}
Z_{x x} & Z_{x y} \\
Z_{y x} & Z_{y y}
\end{array}\right]\left[\begin{array}{l}
H_{x} \\
H_{y}
\end{array}\right],
$$

where $E_{i}, H_{i}(i=x, y)$ are electric and magnetic field spectra and $x, y$ represent the N-S and E-W components, respectively. The impedance responses are transformed into apparent resistivity and phase responses, which are used in the interpretations, modelings and inversions.

Calculation of the impedance responses from the time series data was executed by using the robust processing techniques (Chave et al., 1987). Impedance response data from a period range of between 0.1 and $3000 \mathrm{sec}$ were obtained.

Before inverting the apparent resistivity and phase responses, we first estimated the dimensionality of the resistivity structure by using the criteria of Bahr (1991) to carry out the processing. Although the detailed recipe of Bahr (1991) classifies the behavior of the electromagnetic field into seven classes, we assessed the dimensionality according to the essentials of his criteria, as illustrated in Fig. 4. (Refer to Bahr (1991) for details of the definitions of Swift's (1967) skew, the phase difference skew, and regional skew param-
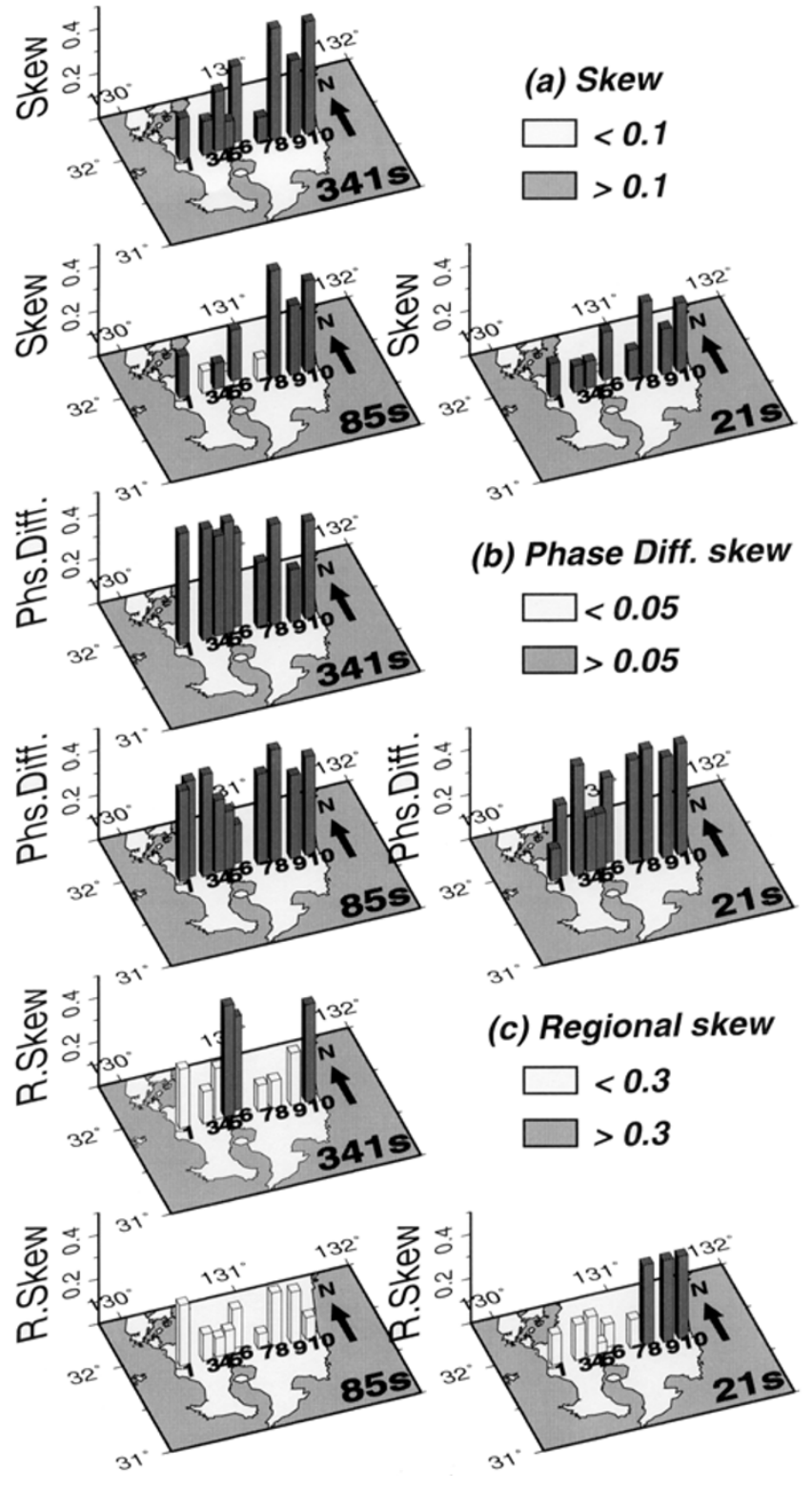

Fig. 5. Dimensionality parameters at 341,85 , and $21 \mathrm{sec}$ periods in the study area. (a) Swift's skew parameter. Gray histograms represent the sites where the parameters are over 0.1. (b) Phase difference skew parameter. Gray histograms indicate the sites where the regional skewness parameters are over 0.05 . (c) Regional skewness parameter. Gray histograms indicate the sites where the regional skewness parameters are over 0.3 .

eters.) The three parameters at the periods of 341,85 , and $21 \mathrm{sec}$ in the study area are presented in Fig. 5. Although Swift's skew parameters are all over 0.1 and the phase difference skew parameters are all over 0.05 , most of the regional skew parameters are less than 0.3 . This result suggests that 3-D/2-D (local 3-D over regional 2-D structure) processing is appropriate for the magnetotelluric data in this study area according to Bahr (1991).

Figure 6 is a rose diagram of the principal axes directions of all the sites for each decade of periods. Each rose diagram is composed of five-degree divisions. In estimating the principal axes directions, we used the decomposition technique developed by Groom and Bailey (1989). We 
$100-1000$ sec

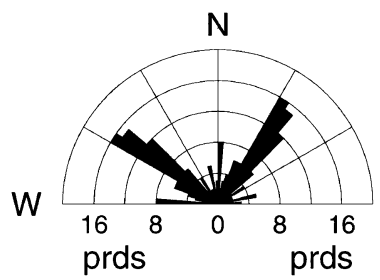

E W

$1-10$ sec

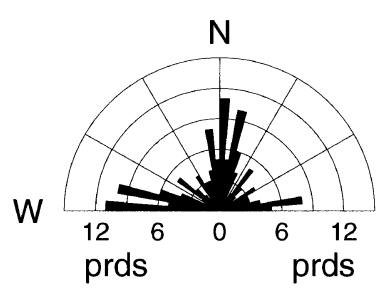

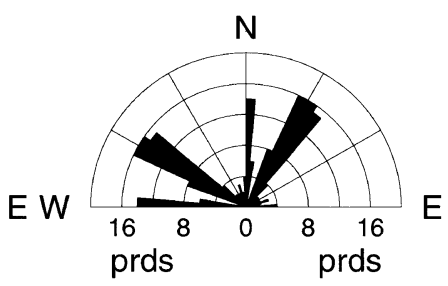

$10-100$ sec

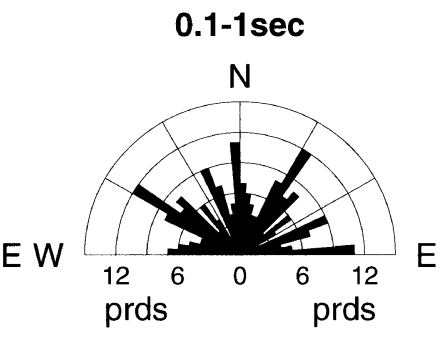

Fig. 6. Rose diagrams of the principal axes accumulated for all sites. The diagrams are represented separately by four period bands. Since the principal axes have uncertainty at $90^{\circ}$, the diagrams are symmetrical at every $90^{\circ}$.

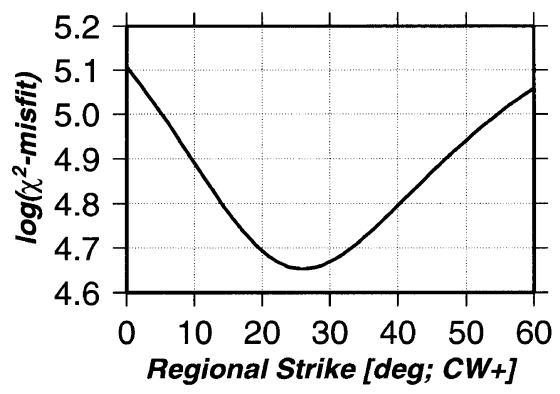

Fig. 7. Plot of 2-D regional strike angles vs. global $\chi^{2}$ misfits calculated from Toh and Uyeshima (1997).

followed the procedure of determinating the distortion parameters (twist and shear) and principal axes directions as recommended by Jones and Groom (1993). We first decomposed the impedance tensors by letting all the parameters be variable with regard to periods and estimated the shear and twist parameters at each site, respectively, and ultimately determined the principal axes directions with the shear and twist parameters fixed at each site. The principal axes directions are almost consistent with each other over longer periods, although they vary widely over shorter periods. The averages of all principal axes directions are $\mathrm{N} 28^{\circ} \mathrm{E}$ and $\mathrm{N} 62^{\circ} \mathrm{W}$. (More prudent calculation of regional strike is proposed by Toh and Uyeshima (1997).) Then we attempted to calculate the regional strike by using the Toh and Uyeshima (1997) calculations in order to test these average values. Figure 7 shows that the sum of $\chi^{2}$ misfits against the regional strike. The sum of $\chi^{2}$ misfits is minimized at the regional strike of $\mathrm{N} 26^{\circ} \mathrm{E}$, which almost coincides with $\mathrm{N} 28^{\circ} \mathrm{E}$. We, therefore, confidently adopted the regional strike as $\mathrm{N} 28^{\circ} \mathrm{E}$, which is approximately parallel to the trench axis.

Figure 8 represents the phase pseudosections of the TE (electric field parallel to the regional strike and magnetic field

\section{$A(W N W)$ (ESE) A}
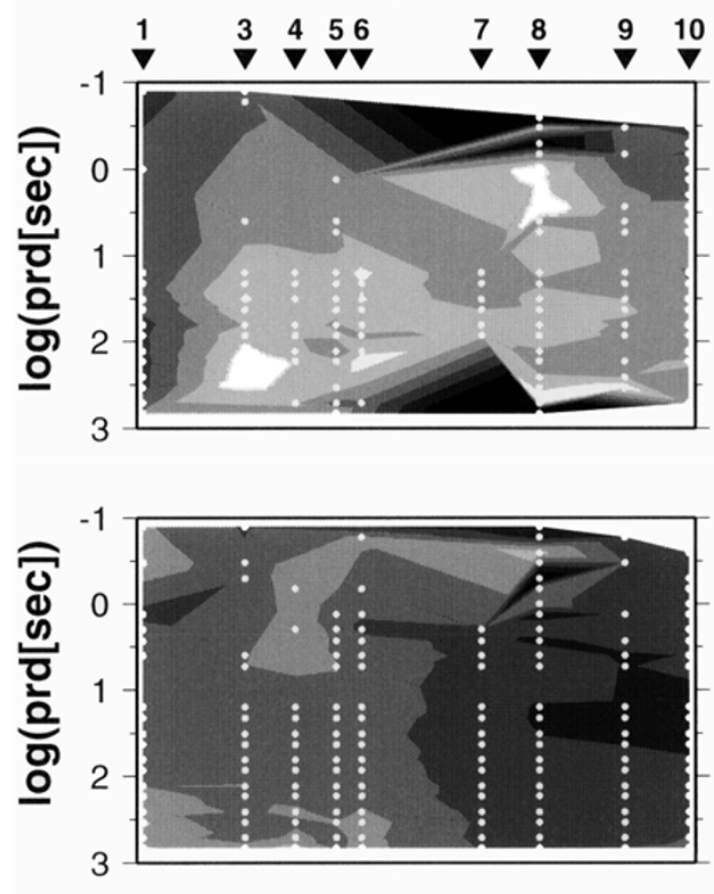

$20 \mathrm{~km}$

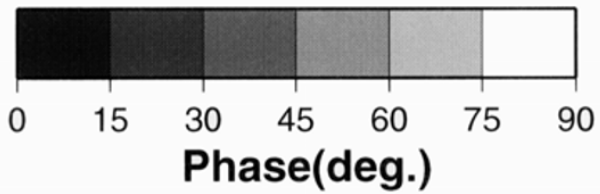

Fig. 8. Phase pseudosections of TM mode (top) and TE mode (bottom) along the $\mathrm{A}-\mathrm{A}^{\prime}$ of Fig. 1. White dots represent sampling points.

perpendicular to the regional strike) and TM (magnetic field parallel to the regional strike and electric field perpendicular to the regional strike) modes along the $\mathrm{A}-\mathrm{A}^{\prime}$ profile of Fig. 1. Note that the vertical scale is indicated by a log-period unit and is a non-linear function of depth, because the penetration depth depends on both resistivity and period. We do not present apparent resistivity pseudosections, which are more or less affected by 'static shift' (e.g. Jones, 1988).

Figure 8 implies following two features: (1) low TE-mode and high TM-mode phase values are observed below the easternmost sites between 0.1 and $10 \mathrm{sec}$ periods, which suggests the presence of a resistive block in the eastern shallow part and (2) TE-mode phase values are high below Sites 4 to 6 over short periods, which suggests a possible intrusion of a conductive block into the central part of the profile spreading bilaterally to greater depths.

\section{2-D Inversion}

The 2-D resistivity model along the $\mathrm{A}-\mathrm{A}^{\prime}$ profile was constructed by inverting the apparent resistivity and phase responses of Sites 1 to 10 under the ABIC (Akaike Bayesian Information Criterion) minimization with a smoothness constraint (Uchida, 1993; Uchida and Ogawa, 1993). The resistivity of the oceanic region was constrained to $0.3 \Omega \cdot \mathrm{m}$ and 
A(WSW)

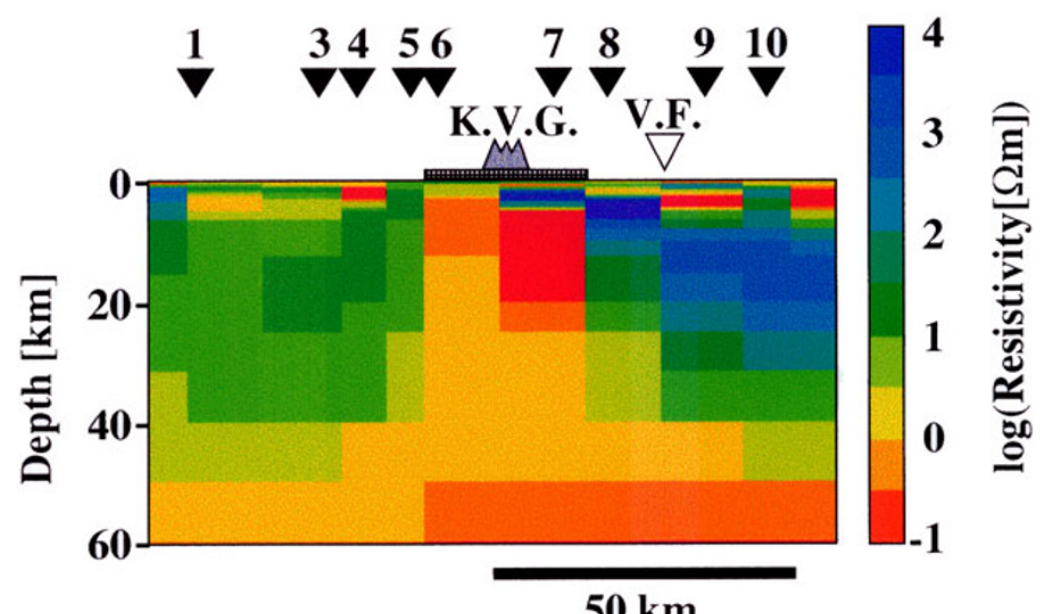

Fig. 9. Final resistivity model along the A-A' profile deduced from 2-D ABIC inversion. K.V.G. and V.F. represent the Kirishima volcano group and volcanic front, respectively.
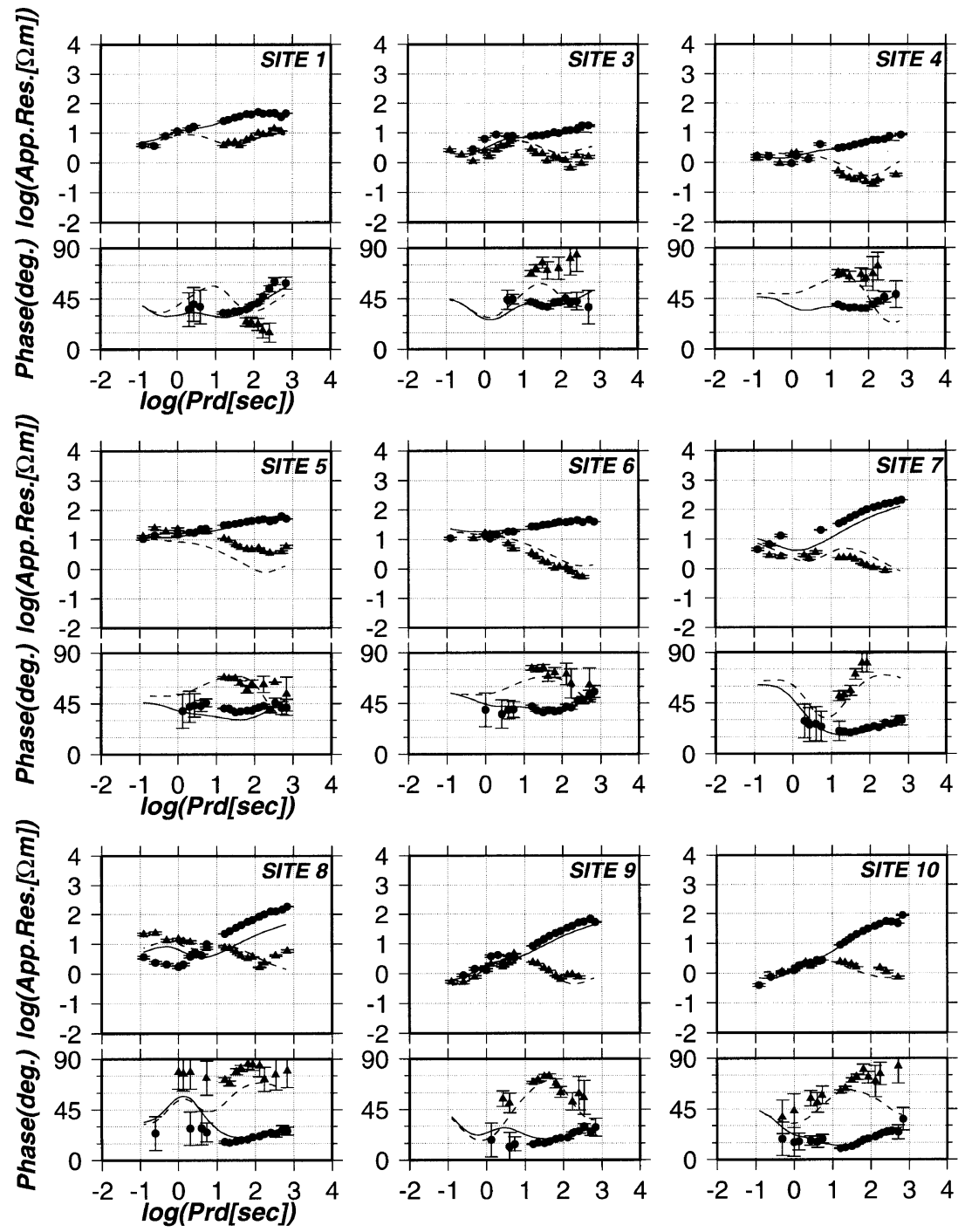

Fig. 10. Observed responses and calculated sounding curves from the final model (Fig. 9). Solid circles: observed responses of the TM mode. Solid triangles: observed responses of TE mode. Solid lines: calculated sounding curves of the TM mode. Broken lines: calculated sounding curves of the TE mode. Some observed responses are reduced and were not used in the inversion process owing to missing the trends. 


\section{(a)}

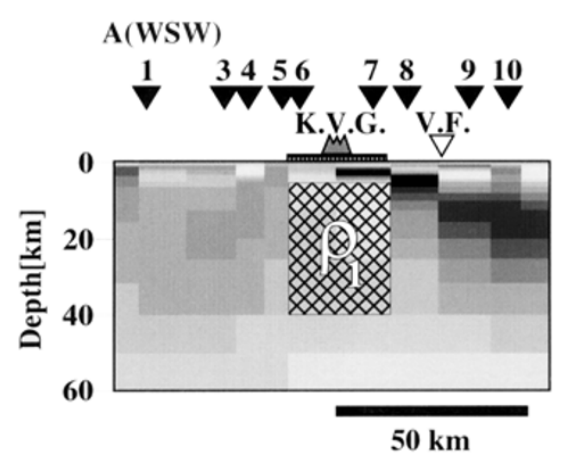

(b)

(c)

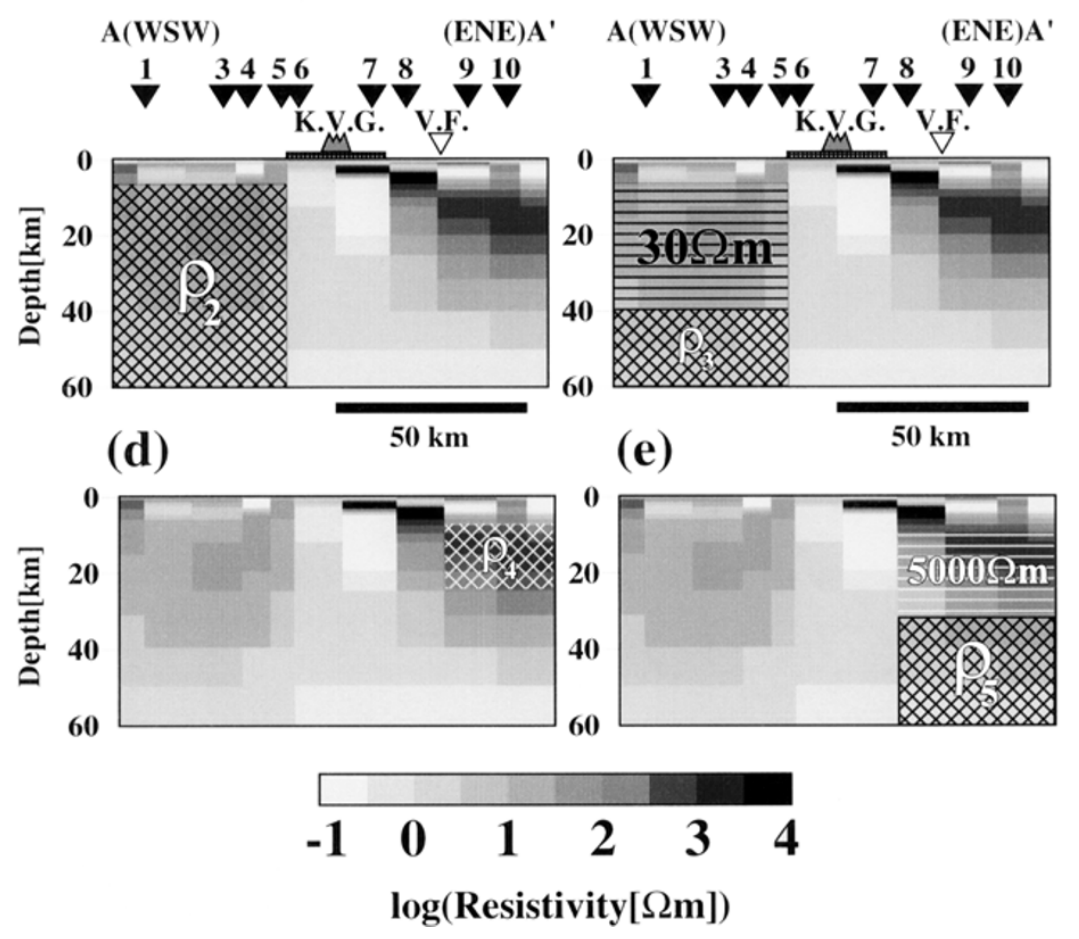

Fig. 11. Modified models to carry out the sensitivity check. (a): The hatched area is replaced by one block with resistivity, $\rho_{2}$, which we varied in the test. (b): Resistivity of the hatched area, $\rho_{2}$, is changed. (c): The upper part of the $\rho_{3}$ block is fixed at $30 \Omega \cdot \mathrm{m}$ and resistivity at a depth of between 40 and $60 \mathrm{~km}, \rho_{3}$ is changed. (d): Resistivity, $\rho_{4}$ is changed. (e): The upper part of the $\rho_{5}$ block is fixed at $5000 \Omega \cdot \mathrm{m}$ and resistivity below $30 \mathrm{~km}$ depth, $\rho_{5}$ is changed.

the starting model was taken to be uniformly $100 \Omega \cdot \mathrm{m}$ except in the oceanic region. Sites are distributed at intervals of between 10 and $15 \mathrm{~km}$ along the $\mathrm{A}-\mathrm{A}^{\prime}$ profile of about $100 \mathrm{~km}$ in length. The profile section of the Earth was divided into $37 \times 44$ meshes. The mesh widths are larger than $5 \mathrm{~km}$ and were determined by the intervals of the adjacent sites. Then we carried out the inversion assuming that the observed responses had small static shifts, because the apparent resistivity responses over the shortest period are almost continuous from site to site along the profile. Thus we inferred that static shifts do not drastically affect the model. After five iterations with 136 degrees of freedom, we obtained the final 2-D resistivity model as shown in Fig. 9. The observed and calculated response curves at each site are compared in Fig. 10. The $\chi^{2}$ misfit, Eq. (2), was reduced from 8.34 to 0.883 .

The model shows that a resistive block of about $3000 \Omega \cdot \mathrm{m}$ is embedded in the middle crust of the eastern part of the profile and a conductor $(1 \sim 30 \Omega \cdot \mathrm{m})$ underlies the resistive block at a depth of from 25 to $40 \mathrm{~km}$. Beneath the Kirishima volcano group, a high conductive block of about $1 \Omega \cdot \mathrm{m}$ can be found which extends bilaterally to below a depth of $40 \mathrm{~km}$. A middle to lower crust seems to be rather uniform to the west of the Kirishima volcano group.

\section{Sensitivity Check}

After obtaining the 2-D resistivity model by using the inversion technique, we carried out the sensitivity tests for some of the typical features.

We appraised the sensitivity by using the $\chi^{2}$ misfit weighted by reciprocal standard errors. It is defined as follows:

$$
\begin{aligned}
& \chi^{2}=S^{2} / D, \\
& S^{2}=\epsilon^{2}+\eta^{2},
\end{aligned}
$$


(a)

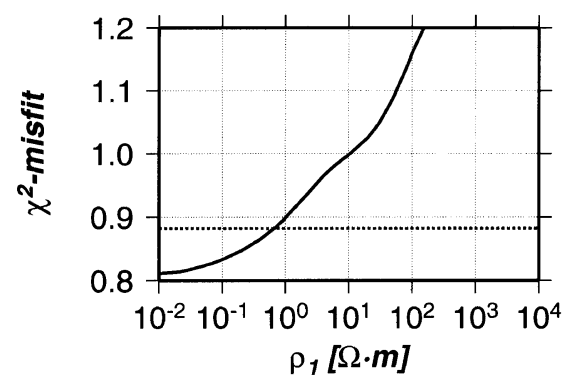

(b)

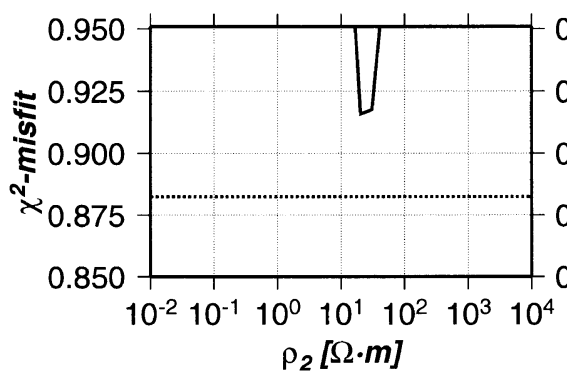

(d)

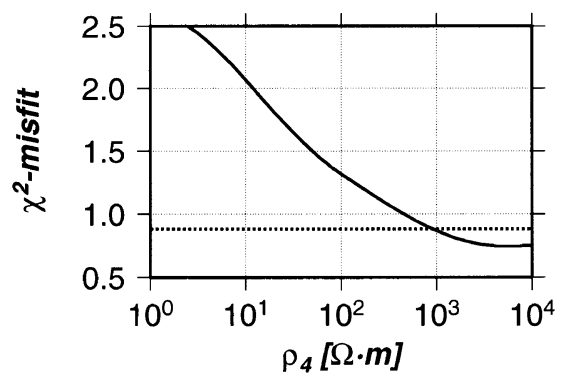

(c) (e)

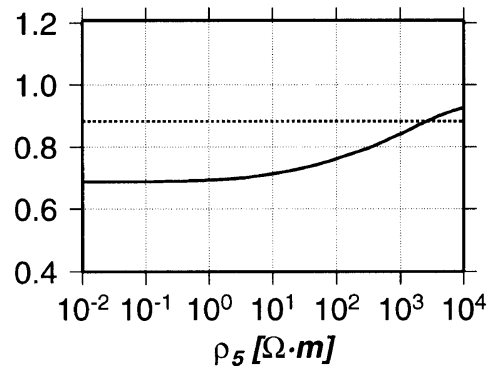

Fig. 12. $\chi^{2}$ misfit calculated from the models of Fig. 11. (a): the $\chi^{2}$ misfit vs. resistivity, $\rho_{1}$, in Fig. 11(a). (b): the $\chi^{2}$ misfit vs. resistivity, $\rho_{2}$, in Fig. 11(b). (c): the $\chi^{2}$ misfit vs. resistivity, $\rho_{3}$, in Fig. 11(c). (d): the $\chi^{2}$ misfit vs. resistivity, $\rho_{4}$, in Fig. 11(d). (e): the $\chi^{2}$ misfit vs. resistivity, $\rho_{5}$, in Fig. $11(e)$. Dotted lines denote the $\chi^{2}$ misfit calculated from the final model as shown in Fig. 9.

$$
\begin{aligned}
\epsilon^{2} & =\sum_{i=1}^{N_{\rho}} W_{i}\left\{\log \left(\rho_{a}^{\mathrm{obs}} / \rho_{a}^{\mathrm{cal}}\right)\right\}^{2}, \\
\eta^{2} & =\sum_{i=1}^{N_{\phi}} w_{i}\left(\phi^{\mathrm{obs}}-\phi^{\mathrm{cal}}\right)^{2}, \\
W_{i} & =\frac{1 /\left(\sigma_{i}^{\rho}\right)^{2}}{1 / N_{\rho} \sum_{j=1}^{N_{\rho}}\left\{1 /\left(\sigma_{j}^{\rho}\right)^{2}\right\}}, \\
w_{i} & =\frac{1 /\left(\sigma_{i}^{\phi}\right)^{2}}{1 / N_{\phi} \sum_{j=1}^{N_{\phi}}\left\{1 /\left(\sigma_{j}^{\phi}\right)^{2}\right\}},
\end{aligned}
$$

where $D$ is the degree of freedom, $N_{\rho}$ is the apparent resistivity data, $N_{\phi}$ is the phase data, $\rho_{a}$ is the apparent resistivity, $\phi$ is the phase, $\sigma^{\rho}$ is the standard error of the apparent resistivity, and $\sigma^{\phi}$ is the standard phase error, respectively.

The result can be summarized as follows:

\subsection{The conductive block beneath the Kirishima vol- cano group}

The sensitivity of the conductive block beneath the Kirishima volcano group was tested by calculating the $\chi^{2}$ misfit for the various resistivity values of $\rho_{1}$ shown in Fig. 11(a). The resistivity, $\rho_{1}$, was changed as $\mathrm{A} \times 10^{n}$ $(A=1,2, \cdots, 9 ; n=-2,-1, \cdots, 2), 1000,1500,2000$, $\cdots, 9000,9500$, and 10000 .

Figure 12(a) presents the $\chi^{2}$ misfit versus resistivity, $\rho_{1}$, in Fig. 11(a). The misfit calculated from the model of Fig. 11(a) for $\rho_{1}>1 \Omega \cdot \mathrm{m}$ is worse than that of the final model. This result implies that the conductive block is well determined beneath the Kirishima volcano group.

\subsection{The spacial extent of the conductive block in the} western side of the Kirishima volcano group

To confirm the lateral extent of the conductive block in the western side of the Kirishima volcano group, we tested the sensitivity of the conductive block below depth of $40 \mathrm{~km}$. We examined the changes in the $\chi^{2}$ misfit for changes in the resistivities, $\rho_{2}$ and $\rho_{3}$, as shown in Fig. 11(b) and 11(c). The way of changing the resistivity is the same as in the previous case.

Figure 12(b) shows the $\chi^{2}$ misfit versus resistivity, $\rho_{2}$, in Fig. 11(b). The $\chi^{2}$ misfit values were found to be much larger than those calculated from the final model. We carried out 
the F-test (Agarwal et al., 1993; Weaver and Agarwal, 1993; Agarwal and Weaver, 1997). The deterioration of fit, $\Delta S^{2}$, is defined as

$$
\Delta S^{2}=\frac{\left(S_{\text {test }}^{2}-S_{\text {final }}^{2}\right) / 2}{\chi_{\text {final }}^{2}},
$$

where $S^{2}$ is provided by Eq. (3) and the subscripts test and final represent tested and final models, respectively. On the F-test, the deterioration for the present case is 5.15, which is greater than 4.79 of a $99 \%$ confidence level. This result deduces that the resistivity structure cannot be approximated by a uniform resistivity block between a depth of 5 and $60 \mathrm{~km}$ in the western side of the Kirishima volcano group .

Figure 12(c) presents the $\chi^{2}$ misfit versus resistivity, $\rho_{3}$, in Fig. 11(c). The misfit calculated from the model of Fig. 11(c) for $\rho_{3}<10 \Omega \cdot \mathrm{m}$ approaches that calculated from the final model. The $\Delta S^{2}$ is 0.723 and is much smaller than 4.79 of a $99 \%$ confidence level. These results reveal that the considered part should be represented by two blocks and the lower block is more conductive than the upper block.

\subsection{The resistive block in the forearc region}

The sensitivity test for the resistive block in the forearc region was carried out by calculating the $\chi^{2}$ misfit for the various resistivity values of $\rho_{4}$ shown in Fig. 11(d). Figure $12(\mathrm{~d})$ presents the $\chi^{2}$ misfit versus resistivity, $\rho_{4}$. The misfit is obviously larger than that calculated from the final model, as $\rho_{4}$ decreases below $1000 \Omega \cdot \mathrm{m}$. This indicates that the resistive block is surely more resistive than its surroundings.

\subsection{The conductive block in the forearc region}

To check the resolution of the conductive block below a $30 \mathrm{~km}$ depth in the forearc region, we calculated the $\chi^{2}$ misfit by changing the resistivity, $\rho_{5}$ shown in Fig. 11(e). The shallower resistive block was constrained at $5000 \Omega \cdot \mathrm{m}$. Figure $12(\mathrm{e})$ presents the $\chi^{2}$ misfit versus resistivity, $\rho_{5}$. Even if $\rho_{5}$ is increased up to $2500 \Omega \cdot \mathrm{m}$, the $\chi^{2}$ misfit remains below the 0.883 that was calculated from the final model. However, the misfit is evidently small as the resistivity below the $30 \mathrm{~km}$ depth in the forearc region decreases. Hence, Fig 12(e) indicates the block below $30 \mathrm{~km}$ depth is preferably conductive in the forearc region, although its resolution is not so good.

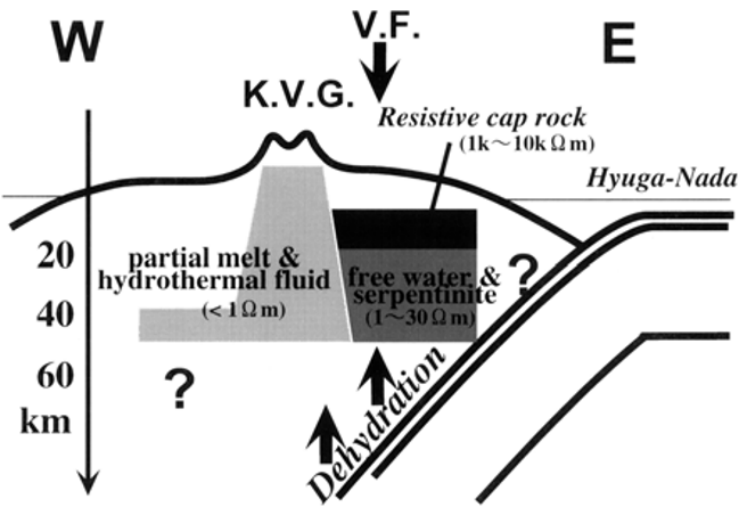

Fig. 13. Interpretation of the 2-D resistivity model. K.V.G and V.F. represent the Kirishima volcano group and volcanic front, respectively. See the text for detail.

\section{Discussion}

A geological interpretation of the final 2-D resistivity model is illustrated in Fig. 13.

Our final model suggested that a high conductive block underlies the active volcanic zone of the Kirishima volcano group. Because of the geological setting, this conductive block may be interpreted as the presence of partial melting and/or geothermal fluid that are directly related to the present magmatism. The bulk resistivity of rocks is mostly controlled by the resistivity, connection, and volume fraction of the pore fluid or melt (Archie, 1942; Bahr, 1997), and the resistivity of the melt is lower than that of brine (Presnall et al., 1972; Rai and Manghnani, 1978). Therefore, we may exclude the presence of free water as a possible cause of the low resistivity. Is such a very conductive structure below 1 $\Omega \cdot \mathrm{m}$ really possible and able to be explained by partial melting and/or geothermal fluid? Recently, Schwarz and Krüger (1997) calculated the bulk resistivity of a medium which is composed of a matrix and isolated spherical melt fractions. The resistivity of the matrix was constrained to $1000 \Omega \cdot \mathrm{m}$ and that of the melt was constrained to $0.1 \Omega \cdot \mathrm{m}$. They found that the bulk resistivity was not able to decrease below 500 $\Omega \cdot \mathrm{m}$, even for a $14 \%$ melt fraction. They also simulated the case in which $1 \%$ connectivity is assumed and found that the bulk resistivity easily reaches about $1 \Omega \cdot \mathrm{m}$. On the other hand, the melt is thought to always exist as thin films or network channels under a mantle condition with partial melting (Toramaru and Fujii, 1986; von Wagen and Waff, 1986; Harte et al., 1993). These studies imply that partial melting can cause a resistivity of below $1 \Omega \cdot \mathrm{m}$. Furthermore, another field exploration also revealed a low resistivity of the order of $1 \Omega \cdot \mathrm{m}$ beneath the Kirishima volcano group (Kagiyama et al., 1996). The conductive area beneath that group extends bilaterally below $40 \mathrm{~km}$ depth. The geometry of the obtained conductive structure seems to correspond well to the features of the magmatic process in the subduction zones analyzed by numerical studies (Spiegelman and McKenzie, 1987; Davies and Stevenson, 1992; Furukawa, 1993), in which the principal stress axes and magma ascending paths in a back arc region point towards a volcanic front on the Earth's surface, called magma focusing.

Another remarkable result is that a lower crust is likely to be conductive in the forearc region. Although our data could not completely confirm the lower crust conductor in that region (hereafter referred to as the forearc conductor), Toh (1993) also found the forearc conductor in the Izu-Bonin arc which is a high-angle subduction zone. The forearc conductor may be a general feature of the resistivity structure of high-angle subduction zones. A particular feature related to the forearc conductor is that the extremely negative Bouguer gravity anomaly is observed in the forearc region (Fig. 2). Okada (1998) constructed a density structure model from the Bouguer gravity anomaly data and concluded that it originated from the low density structure below a $30 \mathrm{~km}$ depth in this area. The depth of the low density structure is roughly consistent with that of the forearc conductor revealed by the present study. If the conductor is caused only by the presence of dehydrated free water, such a negative Bouguer anomaly may not be observed. Hence, we propose that dehydrated free water and serpentinite altered from the free water as a cause 
of the forearc conductor because serpentinite is both low in density and conductive (Stesky and Brace, 1973; Drury and Hyndman, 1979). Toh (1993) also discussed the possibility of the serpentine diapir as a cause of the forearc conductor by referring to the data of serpentine seamount (Ishii et al., 1992) and the hydrous phase of serpentine (Tatsumi, 1989).

A distinct feature is the resistive block of middle crust in the forearc region which seems to play the role of a cap rock trapping free water. A similar result of a resistive block in a forearc region was also obtained in the subduction zone of the eastern part of Hokkaido, northeast Japan by Satoh et al. (1999).

\section{Conclusion}

The resistivity structure of the high-angle subduction zone in the southern Kyushu district was obtained by a magnetotelluric investigation. We found that the lower crust conductor probably occupies in the forearc region and that an extremely conductive block develops beneath the volcanic front. We conjectured that the lower crust conductor is due to a mixture of serpentinite and dehydrated free water, and that the conductive block beneath the volcanic front originates from partial melting.

This study revealed several typical features of the deeper resistivity structure of the high-angle subduction zone, which may reflect the evolution of the subduction system. For example, the conductive column beneath the volcanic front indicates the high heat flow in the mantle wedge, which is a particular feature of the stage of the high-angle subductions in Kanamori's (1977) model.

The dilemma of the lower crust conductor in the forearc region was not resolved enough using only the land data. Hence, we must collect marine data such as OBEM (Ocean Bottom Electromagnetometer) observations to confirm the forearc conductor, and more investigations in other highangle subduction zones are required to establish the general features of the resistivity structure.

Acknowledgments. We thank H. Utada, Y. Sasai, H. Shimizu, N Oshiman, T. Furuzawa, Y. Tanaka and T. Kakuta for their helpful comments, discussion, and critical reading of the manuscript. We also acknowledge M. Teraishi, Y. Sonoda, T. Hashimoto, F. Masutani, Y. Makino and K. Iwakiri for their help with the observations. We are indebted to K. Ishihara, T. Eto and H. Miyamachi for facilitating the observations. For the observation, one of the author (M. I.) was supported by the Faculty of Science, Kagoshima Univ. through the system for extramural research fellowships. A special acknowledgment goes to T. Uchida and Y. Ogawa for providing their MT-inversion programs. We also wish to thank A. Chave for providing the robust estimation program for magnetotelluric responses through the MTNET home page (http://www.cg.NRCan.gc.ca/ mtnet/progs/progs.html). The subsequent version has been greatly improved by $\mathrm{H}$. Toh and $\mathrm{H}$. Brasse. A reference was kindly provided by M. Shimoizumi and M. Nakada. Some of the figures were created by using GMT systems ver. 3.3.2 (Wessel and Smith, 1998). We list those who kindly allowed the observation us to use their sites for observations and for supporting, sustaining, and understanding our scientific research: the Ochiai family in Kiyotake, Miyazaki Prefecture, S. Morinaga in Saito, Miyazaki Prefecture, S. Shirakawada in Miyanojo, Kagoshima Prefecture, FujikawaSanrin Co. Ltd., Kirishima-Tsuma Shrine, Miyanojo Town Office, Yokogawa Town Office, Miyazaki Prefectural Office, Miyazaki District Forestry Office and Aya District Forestry Office.

\section{References}

Agarwal, A. K. and J. T. Weaver, Two-dimensional inversion of Papua New Guinea data using 'least-blocked' models, J. Geomag. Geoelectr., 49, 827-842, 1997.

Agarwal, A. K., P. E. Poll, and J. T. Weaver, One- and two-dimensional inversion of magnetotelluric data in continental region, Phys. Earth Planet. Inter, 81, 155-176, 1993.

Archie, G. E., The electrical resistivity log as an aid in determining some reservoir characteristics, Trans. Am. Inst. Mining Eng., 146, 54-62, 1942.

Bahr, K., Geological noise in magnetotelluric data: a classification of distortion types, Phys. Earth Planet. Inter., 66, 24-38, 1991.

Bahr, K., Electrical anisotropy and conductivity distribution functions of fractal random networks and of the crust: the scale effect of connectivity, Geophys. J. Int., 130, 649-660, 1997.

Chave, A. D., D. J. Thomson, and M. E. Ander, On the robust estimation of power spectra, coherences, and transfer functions, J. Geophys. Res., 92, 633-648, 1987.

Davies, J. H. and D. J. Stevenson, Physical model of source region of subduction zone volcanics, J. Geophys. Res., 97, 2037-2070, 1992.

Drury, M. J. and R. D. Hyndman, The electrical resistivity of oceanic basalt, J. Geophys. Res., 84, 4537-4545, 1979.

Furukawa, Y, Magmatic processes under arcs and formation of the volcanic front, J. Geophys. Res., 98, 8309-8319, 1993.

Gamble, T. D., W. M. Goubau, and J. Clarke, Magnetotellurics with a remote magnetic reference, Geophysics, 44, 53-68, 1979.

Groom, R. W. and R. C. Bailey, Decomposition of magnetotelluric impedance tensors in the presence of local three-dimensional galvanic distortion, J. Geophys. Res., 94, 1913-1925, 1989.

Harte, B., R. H. Hunter, and P. D. Kinny, Melt geometry, movement and crystallization, in relation to mantle dykes, veins and metasomatism, Phil. Trans. Soc. Lond., Series A, 342, 1-21, 1993.

Hyndman, R. D., Dipping seismic reflectors, electrically conductive zones and trapped water in the crust over a subducting plate, J. Geophys. Res., 93, 13391-13405, 1988.

Ishihara, K. and A. Yoshida, Configuration of the Philippine Sea slab and seismic activity in and around Kyushu, Zisin, 45, 45-51, 1992 (in Japanese with English abstract).

Ishii, T., P. Robinson, H. Maekawa, and R. Fiske, Petrological studies of peridotites from diapiric serpentine seamounts in the Izu-Ogasawara-Marina forearc, in Proceedings of Ocean Drilling Program, Science Results, 125 , 445-485, 1992.

Jarrard, R. D., Relations among subduction parameters, Rev. Geophys., 24, 217-284, 1986.

Jones, A. G., Static shift of magnetotelluric data and its removal in a sedimentary basin environment, Geophysics, 53, 967-978, 1988.

Jones, A. G. and R. W. Groom, Strike-angle determination from the magnetotelluric impedance tensor in the presence of noise and local distortion rotate at your peril!, Geophys. J. Int., 113, 524-534, 1993.

Kagiyama, T., H. Utada, M. Uyeshima, F. Masutani, W. Kanda, Y. Tanaka, H. Masuda, H. Murakami, I. Shiozaki, M. Ichiki, T, Yukutake, T. Mogi, K. Amita, N. Oshiman, and M. Mishina, Resistivity structure of the central and the southeastern part of Kirishima volcanoes, Bull. Volcanol. Soc. Japan, 41, 215-225, 1996 (in Japanese with English abstract).

Kakuta, T., H. Miyamachi, and A. Takagi, Intermediate earthquakes in a northern part of the Kyushu-Ryukyu arc, Zisin, 44, 63-74, 1991 (in Japanese with English abstract).

Kanamori, H., Seismic and aseismic slip along subduction zones and their tectonic implications, in Island Arcs, Deep Sea Trenches and Back-Arc Basins, Maurice Ewing Series, vol. 1, pp. 162-174, AGU, 1977.

Kobayashi, S., R. Shichi, S. Onizawa, J. Oikawa, and H. Watanabe, Gravity anomaly in southern Kyushu, Japan, in Proceedings of 1997 Conductivity Anomaly Symposium, 275-281, 1997 (in Japanese).

Kurtz, R. D., J. M. DeLaurier, and J. C. Gupta, A magnetotelluric sounding across Vancouver Island detects the subducting Juan de Fuca plate, Nature, 321, 596-599, 1986.

Nagamune, T. and H. Tashiro, Shape of the Wadati-Benioff zone beneath Kyushu, Japan, Zisin, 42, 13-19, 1989 (in Japanese with English abstract).

Okada, N., Subsurface structure inferred from gravity anomaly and seismic velocity structure in eastern Kyushu, Graduation Thesis, Kyushu Univ. 33 pp., 1998 (in Japanese).

Presnall, D. C., C. L. Simmons, and H. Porath, Changes in electrical conductivity of synthetic basalt during melting, J. Geophys. Res., 77, 5665-5672, 1972.

Rai, C. S. and M. H. Manghnani, Electrical conductivity of ultramafic rocks 
to 1820 Kelvin, Phys. Earth Planet. Inter., 17, 6-13, 1978.

Satoh, H., Y. Nishida, Y. Ogawa, Y. Sasai, M. Uyeshima, M. Takeda, and M. Kasahara, Crustal and uppermantle resistivity structure in the eastern part of the Hokkaido, Japan-Integration analysis of wideband-MT and network-MT data-, in Proceedings of 1999 Conductivity Anomaly Symposium, 38-46, 1999 (in Japanese).

Schwarz, G. and D. Krüger, Resistivity cross section through the southern central Andes as inferred from magnetotelluric and geomagnetic deep soundings, J. Geophys. Res., 102, 11957-11978, 1997.

Seno, T., S. Stein, and A. E. Gripp, A model for the motion of the Philippine sea plate consistent with NUVEL-1 and geological data, J. Geophys. Res., 98, 17941-17948, 1993.

Shiozaki, I., The study of the electrical resistivity structures beneath the Chugoku and Shikoku district, Ph.D. Thesis, Kobe Univ., 204 pp., 1993 (in Japanese).

Spiegelman, M. and D. McKenzie, Simple 2-D models for melt extraction at mid-ocean ridges and island arcs, Earth Planet. Sci. Lett., 83, 137-152, 1987.

Stesky, R. M. and W. F. Brace, Electrical conductivity of serpentinized rocks to 6 kilobars, J. Geophys. Res., 78, 7614-7621, 1973.

Tatsumi, Y., Migration of fluid phases and genesis of basalt magmas in subduction zones, J. Geophys. Res., 94, 4697-4707, 1989.

Toh, H., Electrical conductivity structure of the Izu-Bonin arc revealed by seafloor electromagnetic observations, Ph.D. Thesis, Univ. of Tokyo, 215 pp., 1993.

Toh, H. and M. Uyeshima, One-dimensional model study of the PNG dataset using site-independent Groom-Bailey decomposition, J. Geomag. Geoelectr., 49, 843-856, 1997.

Toramaru, A. and N. Fujii, Connectivity of melt phase in a partially molten peridotite, J. Geophys. Res., 91, 9239-9252, 1986.

Uchida, T., Smooth 2-D inversion for magnetotelluric data based on statistical criterion ABIC, J. Geomag. Geoelectr., 45, 841-858, 1993.

Uchida, T. and Y. Ogawa, Development of FORTRAN code for two-dimensional magnetotelluric inversion with smoothness constraint, Open-File Report, Geological Survey of Japan, No. 205, 115 pp., 1993.

Utada, H., A direct inversion method for two-dimensional modeling in the geomagnetic induction problem, Ph.D. Thesis, Univ. of Tokyo, 409 pp., 1987.

Uyeda, S. and H. Kanamori, Back-arc opening and the mode of subduction, J. Geophys. Res., 84, 1049-1061, 1979.

von Wagen, N. and H. S. Waff, Wetting of enstatite by basaltic melt at $1350^{\circ} \mathrm{C}$ and 1.0- to 2.5-GPa pressure, J. Geophys. Res., 93, 1153-1158, 1986.

Wannamaker, P. E., J. R. Booker, A. G. Jones, A. D. Chave, J. H. Filloux, H. S. Waff, and L. K. Law, Resistivity cross section through the Juan de Fuca subduction system and its tectonic implications, J. Geophys. Res., 94, 14127-14144, 1989

Weaver, J. T. and A. K. Agarwal, Automatic 1-D inversion of magnetotelluric data by the method of modelling, Geophys. J. Int., 112, 115-123, 1993.

Wessel, P. and W. H. F. Smith, New, improved version of Generic Mapping Tools released, EOS Trans. $A G U, \mathbf{7 9}, 579,1998$.

Yamazaki, F. and T. Ooida, Configuration of subducting Philippine Sea plate beneath the Chubu district, central Japan, Zisin, 38, 193-201, 1985 (in Japanese with English abstract).

M. Ichiki (e-mail: ichiki@eri.u-tokyo.ac.jp), N. Sumitomo, and T. Kagiyama 